\title{
Anchorage of naturally corroded, plain reinforcement bars in flexural members
}

\author{
Samanta Robuschi · Karin Lundgren · Ignasi Fernandez • Mathias Flansbjer
}

Received: 28 March 2019/ Accepted: 11 March 2020/Published online: 26 March 2020

(C) The Author(s) 2020

\begin{abstract}
Reinforced concrete structures are often damaged by corrosion, which affects the interaction between reinforcement bars and concrete. Earlier studies mostly applied artificial corrosion to test the bond between deformed bars and concrete. However, there is a lack of knowledge on the effects of natural corrosion on plain bars. In this paper, 20 beams with naturally corroded plain bars and varying amount of damage were taken from an 80-year-old bridge and tested in three-point bending. All but three of the specimens anchored the yield force of the bars after the opening of one or two major bending cracks. At large deflections, the load-carrying mechanism changed from beam to arch action. Eventually, end-slip of the reinforcement bars was observed. The bars were extracted, cleaned, three-dimensionally scanned, and
\end{abstract}

Electronic supplementary material The online version of this article (https://doi.org/10.1617/s11527-020-01471-2) contains supplementary material, which is available to authorized users.

S. Robuschi $(\bowtie) \cdot$ K. Lundgren · I. Fernandez .

M. Flansbjer

Division of Structural Engineering, Department of

Architecture and Civil Engineering, Chalmers University

of Technology, 41296 Göteborg, Sweden

e-mail: samanta.robuschi@chalmers.se

M. Flansbjer

Division Safety and Transport, Mechanics Research, RISE Research Institute of Sweden, Brinellgatan 4,

50462 Borås, Sweden tested in tension. The average bond strength in the unyielded zone was found to be equal to $7.39 \mathrm{MPa}$, with a standard deviation of $3.33 \mathrm{MPa}$. The casting position was identified as an important factor: when uncorroded, bottom-cast bars had a higher bond strength than that of top-cast bars. However, they were more prone to splitting cracks and, consequently, loss of bond strength for small corrosion levels. Topcast bars had increasing bond strength with increasing corrosion levels, owing to the absence of external cracks. These differences were likely related to a denser concrete surrounding the bottom-cast bars. The remaining bond capacity in the yielded zones was evaluated to be approximately 1.0 MPa.

Keywords Concrete $\cdot$ Post-yielding $\cdot$ Bond strength · Plain bars · Natural corrosion - Three-point bending test

\section{Introduction}

Today's increasing demand for load-carrying capacity needs to be sustained, for the most part by ageing and possibly deteriorating infrastructure. Furthermore, climate change is foreseen to aggravate the decay of concrete structures in the forthcoming years. Higher carbon dioxide concentrations, warmer climates and an increasing number of freezing cycles will affect the corrosion process, with earlier initiation and increased 
corrosion rates [1]. The current situation calls for proper methods for the structural assessment of structures that are currently in use. Assessment methods for existing structures are treated in codes and are already the topic of many research projects [2-4]; however, little focus is given to structures with plain bars. RC structures built with plain reinforcement bars is an older construction practice. Plain bars are characterized by lower anchorage capacity with respect to ribbed bar, hence the bars were commonly bent in end-hooks in the anchorage region. Thus, the study of the anchorage of plain bars is divided in two interconnected problems [5]: the contribution to the anchorage given by the plain bars, and the contribution of the hooks. This work focuses on the first one.

Despite presently plain bars are rarely used owing to their lower anchorage capacity, many structures built with this type of reinforcements are still in use and need proper assessment [6]. The use of plain bars drastically diminished prior to the mid-1960s, although there are large differences between countries. In Sweden, plain bars ceased to be used in the 1940s. In Italy, plain bars were used up to the 1980s and a large part of this country's infrastructure is still built with plain reinforcement bars [7]. Furthermore, most of the remaining structures with plain bars were built with materials and techniques different from those in use today. This adds an additional challenge to their assessment.

Corrosion is one of the most common forms of damage in reinforced concrete (RC) structures [8]. Therefore, understanding its effects and development is mandatory when assessing existing structures. The corrosion process initiates when reinforcement bars depassivate. This can be caused by many factors, the most common being carbonation and chloride penetration. This phenomenon affects the overall structural behaviour and decreases the safety of the structure in different ways [9]:

1. Corrosion products occupy a larger volume than that of uncorroded steel. This leads to an increase in mechanical pressure both on the bar and on the surrounding concrete.

2. Corrosion changes the properties of the bar itself; by reducing the cross section of the bar it decreases both the strength and the ductility.
3. Corrosion introduces a layer of corrosion product that is substantially weaker than the original steelconcrete interface.

Many studies focus on how corrosion affects the bond between reinforcement bars and concrete. The bond is commonly studied as a result of three mechanisms: chemical adhesion, friction, and mechanical interlocking between the ribs and the concrete. In the case of plain bars, friction and chemical adhesion play a more fundamental role than in the case of deformed bars. Mechanical interlock acts only at a micro-level, between the concrete and the roughness of the reinforcement bar. Sliding friction [10], to indicate the wedging action of small particles of concrete detached by the initiation of the slip, also contributes to the mechanical interlock. As a result of the smaller mechanical interlock, the bond strength of plain bars is naturally lower than that of deformed bars and strongly relies on friction. Consequently, normal pressure is foreseen to have a large impact on the bond strength of plain bars [9]. Thus, the bond between plain bars and concrete is expected to be heavily affected by corrosion: if no cracks are present in the anchorage region, the increase in mechanical pressure would noticeably increase friction by increasing the normal stresses on the plain bar [11]. However, an excessive amount of pressure would cause the cover to crack and spall. The casting position is another parameter that could affect the friction component of the bond. Top-cast bars are more likely to be surrounded by a less dense concrete, as result of the settlement of the aggregate below the bar and of the accumulation of bleed water at the bar [12]. This would result in a lower bond strength than for bottomcast bars. This effect is more pronounced for plain bars than for deformed ones [13]. Furthermore, plain bars generate less splitting stresses, owing to the absence of ribs. By introducing a layer of corrosion product, corrosion affects the friction characteristics of the interface between corroded reinforcement and concrete. However, it was shown in a study [14] that the presence of corrosion product does not impair the friction characteristics of a bar/concrete interface with surface cracks smaller than $1 \mathrm{~mm}$.

Many studies can be found in the literature that combine deformed bars and corrosion, investigating both the link between external damage (such as crack width) and average corrosion level [4] and how 
corrosion and external damage consequently affect the bond strength [14, 15]. In the work published by Sæther [16], an overview of the different aspects that affect the bond deterioration of corroded steel bars embedded in concrete can be found. Few studies are found in the literature that combine plain bars and corrosion. Furthermore, owing to the substantial differences between the bond mechanisms of deformed and plain reinforcement bars, the same assessment methods used for the former are hardly applicable to the latter. A recent study [13] investigated the bond behaviour of plain bars when subjected to artificial corrosion by using of both RILEM pull-out tests and 'beam end' tests, showing important differences in the behaviour of top-cast and bottom-cast bars. Top-cast bars were shown to have a lower bond strength when not affected by corrosion, such that a reduction factor of 0.5 on bond strength due to 'poor casting position' is suggested. The bond strength of top-cast bars was shown to initially increase with the corrosion level. Other factors, such as the confinement provided by stirrups and the increase in concrete cover, were found to be beneficial to the bond strength of plain bars. In a later work [11], Cairns et al. investigated the effect of reinforcement corrosion in concrete beams reinforced with plain bars. A consistent increase in strength was observed in the artificially corroded beams when compared to non-corroded specimens. The additional strength was attributed primarily to the increase in bond due to the confining effect of the corrosion product. Remarks were given on the importance of considering the bond-enhancing effect of the support pressure.

The previously discussed works focus on specimens that were corroded artificially; however, several uncertainties have been raised on how well artificial corrosion methods represent the corrosion process in real structures [17, 18]. Yuan et al. [19] found that different corrosion-induction methods led to different surface characteristics in corroded steel bars: the galvanostatic method generated a homogeneously corroded surface, whereas in natural corrosion conditions the surface corroded heterogeneously. Williamson and Clark [20] tested artificially corroded plain bars with different levels of corrosion (0-20\%) and current densities $\left(0.25-2 \mathrm{~mA} / \mathrm{cm}^{2}\right)$. Current density was found to be responsible for the changes in the morphology of the corrosion product and, consequently, in the bond strength. Hence, testing naturally corroded specimens taken from decommissioned structures offers an alternative to the use of artificial corrosion methods. This allows for the study of damage due to many factors influencing the ageing process of RC structures, such as creep, freezing, and shrinkage. In recent years, more studies on naturally corroded specimens have been successfully conducted, with the aim of linking visible damage in existing structures to the corrosion type, level, characteristic and, ultimately, structural capacity [15, 21]. However, to the best knowledge of the authors, there is no published study on specimens with naturally corroded, plain reinforcement bars. The aim of this work was to investigate the anchorage of plain bars in deteriorated, existing, older structures experimentally. The material at the time of construction (1935) was investigated, and significant differences from the materials used today were observed, both in the steel bars and the concrete mixture.

\section{Experiments}

\subsection{Overview}

In Fig. 1, an overview of the presented investigation is shown: 20 beams were cut from the edge beams of Gullspång Bridge and then tested in three-point bending. In all but three flexural tests, bending cracks were followed by yielding of the tensile reinforcement, and, thereafter, end-slips of the bars were observed. After the structural testing, the bars were extracted from the beams, cleaned and scanned, to evaluate corrosion level and yield penetration, and then tested in tension. Finally, the bond strength of the unyielded zone and the loss of bond strength at yielding were evaluated.

\subsection{Specimens}

Gullspång Bridge was built in 1935 and demolished in 2016 owing to heavy corrosion damage. The edge beams were carefully taken out, cut into segments, and designated to be used for research. The beams presented different cracks on their surface, and spalling strongly affected the geometry in some locations. This is the result of being exposed for 81 years to weather conditions that included snow, 


\section{Gullspång bridge}

$1935-2016$

$50 \mathrm{~m}$

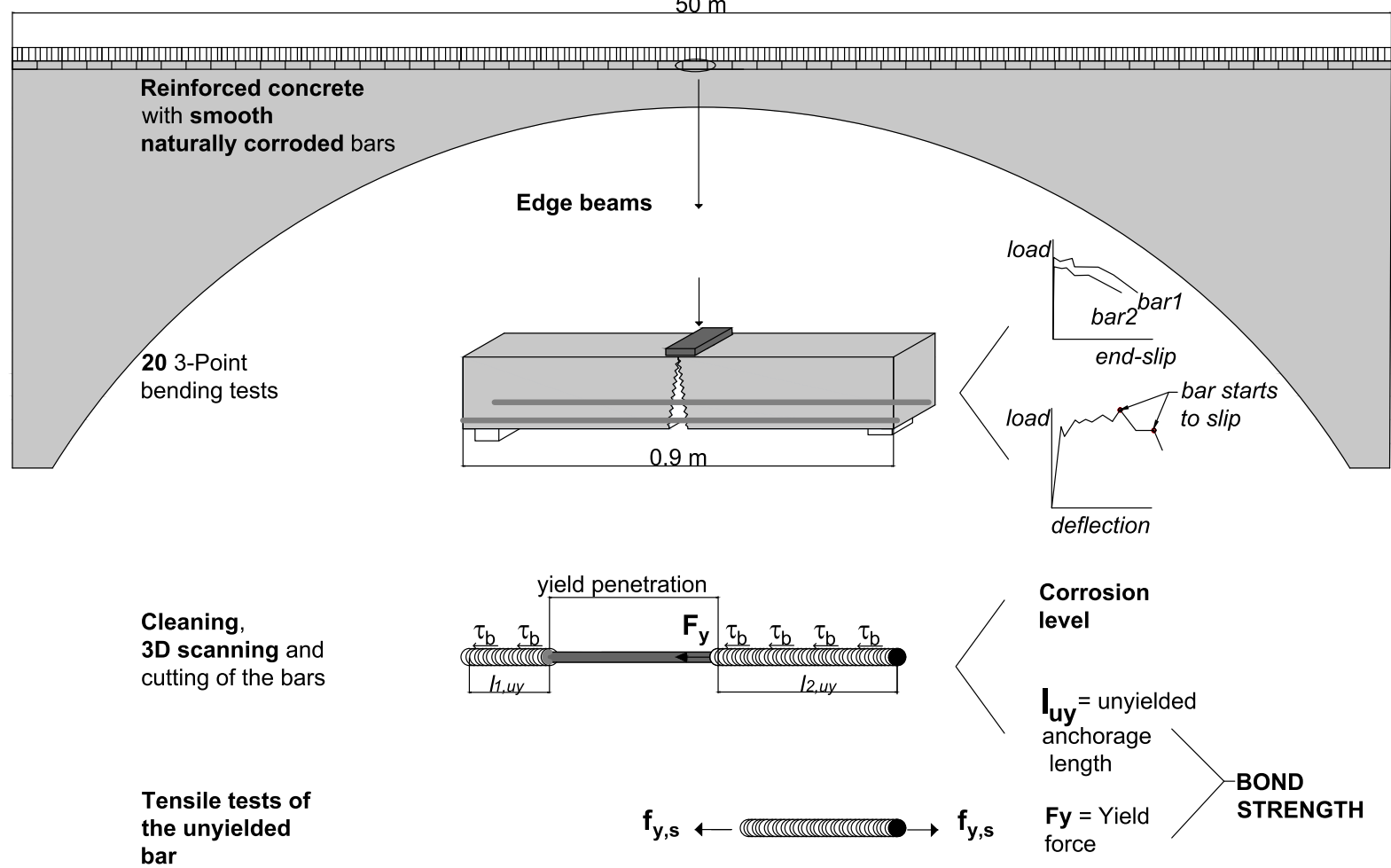

Fig. 1 Overview of the tests carried out on the specimens from Gullspång bridge

freezing cycles, and wind, as well as to de-icing salts and traffic loads. Signs of corrosion were clearly visible but not uniformly distributed.

The edge beams were characterised by $\phi 6$ stirrups (Fig. 2), open on the bottom side with respect to the original position on the bridge and $2 \phi 16$ plain reinforcement bars, top and bottom. The concrete cover varied approximately between 20 and $55 \mathrm{~mm}$, but was reported to be equal to $34 \mathrm{~mm}$ in the original

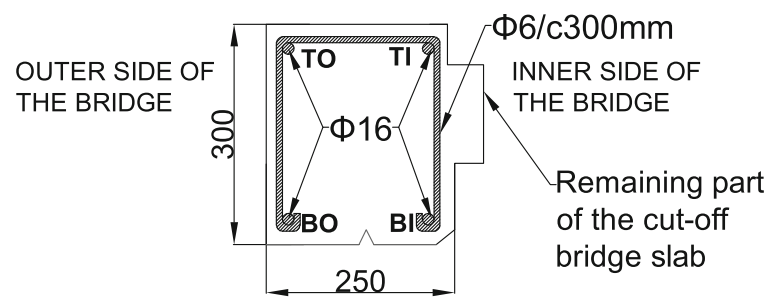

Fig. 2 Geometry of the cross section (according to the original drawings) together with two different cross sections of the edge beams as positioned on the bridge. The bars are labelled as follows: $\mathrm{TO}=$ top-outer, $\mathrm{TI}=$ top-inner, $\mathrm{BO}=$ bottom-outer, drawings. Average cross-section dimensions were $300 \times 250 \mathrm{~mm}$. All specimens contained an approximately $50 \mathrm{~mm}$ portion of the slab deck, sticking out on the inner side. The stirrup spacing diverged from the originally prescribed $300 \mathrm{~mm}$. There was great variation, ranging from approximately 100 to $450 \mathrm{~mm}$. Similarly, great variation was observed in the concrete cover and in the diameter of the bars. Tensile tests from the time of construction reported the diameter of
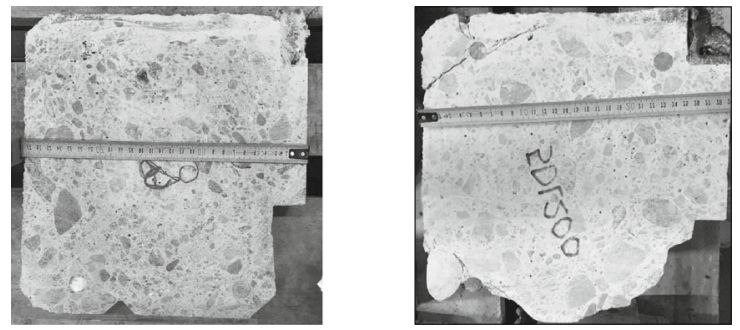

and $\mathrm{BI}=$ bottom-inner. The remaining part of the cut-off bridge slab is clearly visible to the right. All dimensions are in millimeters 
the reinforcement bars as equal to $16.2 \mathrm{~mm}$, in contrast to the $16 \mathrm{~mm}$ reported by the original drawings. The actual average diameter seemed to be in between the two values (Table 1). The reinforcement bars in the edge beams were anchored by means of end-hooks, as typical of RC structures with plain bars. The spacing between the hooks was between 6 and $8 \mathrm{~m}$. The sections of the edge beams with hooks were not used in the tests presented in this paper, but cut and saved for being tested in future research.

Cracks and differences in geometry were carefully inspected and documented. An optical microscope was used for the measurement of the average opening of the cracks, while their location and length were documented and photographed. The data on cracks were used to group the anchorage zones into three different categories: anchorage zones with cracks smaller than $0.5 \mathrm{~mm}(\mathrm{C} 1)$, anchorage zones with cracks between 0.5 and $1 \mathrm{~mm}(\mathrm{C} 2)$, and anchorage zones with cracks bigger than $1 \mathrm{~mm}$ of the average opening (C3). Additional categories, namely, 'reference' (R) and 'severely damaged' (S) were added to provide low and upper bound groupings of the damage state. (For visual examples of the classification, see Figure A in the supplementary material.)

In the original drawings of the bridge, data on the material properties were given. The prescribed concrete had a compressive strength equal to or higher than $30 \mathrm{MPa}$, and the prescribed reinforcement bars had a yield stress equal to or higher than $300 \mathrm{MPa}$. Nevertheless, tests carried out during construction already showed a yield stress of approximately $250 \mathrm{MPa}$. Therefore, the material specification from the original drawings could not be fully relied upon. Additionally, hardening of concrete was expected owing to ageing. In a field survey done in 1988, the concrete compressive strength was measured to be approximately $45 \mathrm{MPa}$ and the yield strength of the plain reinforcement bars was measured to be
$252 \mathrm{MPa}$. Investigations on the material properties were carried out in the context of this project, with results confirming the previous data with reasonable approximation. Eight concrete cores $(100 \times 200 \mathrm{~mm})$ were drilled according to EN 12504-1:2009 [22] and tested for cylindrical compressive strength according to EN 12390-3:2009 [23]. The result was an average compressive strength of $45.6 \mathrm{MPa}$, with a standard deviation of 4.6 MPa. Tensile testing of the steel bars is further discussed in Sect. 2.8. It should be noted that steel bars with low yield strength were common at the time of construction.

\subsection{Test set-up}

The test set-up was designed by using pilot tests, as discussed in [24, 25]. A three-point bending test was selected (Fig. 3). The tested beams were $900 \mathrm{~mm}$ long, with a theoretical span of $700 \mathrm{~mm}$. They were supported on one side by a narrow support $(50 \times 100 \mathrm{~mm})$ and on the opposite side by a full support $(50 \times 250 \mathrm{~mm})$. Both the load plate and the two supports consisted of a steel block and a thin wood-fibre layer inserted between the steel and the concrete. The narrow support was introduced to support the beam directly while minimising the support pressure on the longitudinal reinforcing bars. The use of two narrow supports was considered too risky to safely position the beam into place and for testing. It was preferred to use a full support on one of the sides and observe the effect of the two different supports on anchorage. A loading plate of $90 \times$ $130 \mathrm{~mm}$ was positioned in the centre of the beam (at a distance of $350 \mathrm{~mm}$ from each support plate axis), at equal distance from each longitudinal bar. At the location of the full support, the ends of the reinforcing bars were initially restrained from anchorage failure by using a bolt/washer configuration, although this design was abandoned after four tests owing to

Table 1 Geometrical information of the Gullspång Bridge reinforcement bars

\begin{tabular}{llll}
\hline Data source & $\hat{A}_{u}\left(\mathrm{~mm}^{2}\right)$ & $\hat{p}_{u}(\mathrm{~mm})$ & $\hat{D}_{u}(\mathrm{~mm})$ \\
\hline Drawings & 201.06 & 50.27 & 16 \\
Field tests (1935) & 206.12 & 50.89 & 16.2 \\
3D Scanner & $\mathbf{2 0 3 . 0 2} \pm \mathbf{2 . 6 9}$ & $\mathbf{5 0 . 5 1} \pm \mathbf{0 . 3 4}$ & $\mathbf{1 6 . 0 8} \pm \mathbf{0 . 1 1}$ \\
\hline
\end{tabular}

In bold, data used in the evaluations in this paper 


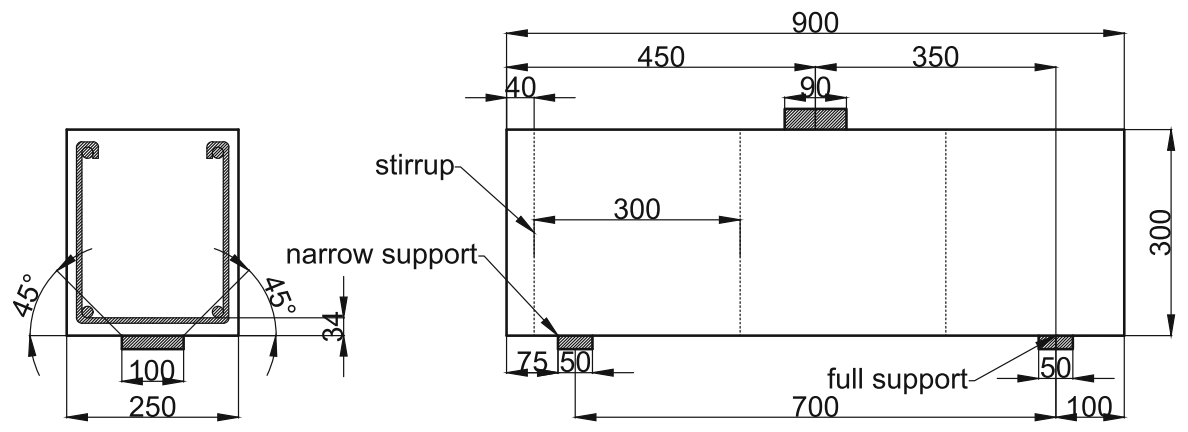

Fig. 3 Experimental set-up and view of the narrow support for a beam tested upside down compared to its position on the bridge

consistent bending of the washers and to unwanted slipping of the restrained tensile reinforcements (two out of four tests). It was opted to monitor the end-slip on both sides for subsequent beams. It was decided that tests would be carried out both with beams as positioned on the bridge and upside down, to account for the effect of different concrete densities on the bond strength of top-cast and bottom-cast bars. For the geometrical properties of each beam, see Table 2 .

\subsection{Monitoring of the structural tests}

The beams were tested by controlling the mid-span deflection: a loading rate of $2 \mathrm{~mm} / \mathrm{min}$ was used up to $35 \mathrm{kN}$, while compressing the wood layers underneath the load and support plates. The load rate was then changed to $1 \mathrm{~mm} / \mathrm{min}$ up to $60 \mathrm{kN}$ to avoid abrupt changes in the loading rate. From $60 \mathrm{kN}$, the loading rate was set to $0.4 \mathrm{~mm} / \mathrm{min}$, to capture the pre-cracking behaviour of the beam in detail. It was increased again to $1 \mathrm{~mm} / \mathrm{min}$ after the recorded deformation had reached $10 \mathrm{~mm}$. Displacements and crack openings were captured with digital image correlation (DIC), and linear variable displacement transformers (LVDTs). Crack information, including formation patterns and opening widths, was recorded using DIC. Images of the tests were acquired at a rate of 1/7 Hz. DIC was set to monitor the external side of each beam, i.e. the outer side of the edge beams as positioned on the bridge. An ARAMIS ${ }^{\circledR}$ adjustable stereo camera system [26] was used. The surface of each beam was painted in white. Subsequently, black paint was applied with the help of a brush to generate a random pattern that would allow the acquisition of geometrical data (Fig. 4). The results were subsequently processed by using the software GOM ${ }^{\circledR}$ Correlate [27]. LVDTs were used to monitor the end-slips of the bars and to control the displacement of the hydraulic jack (and, consequently, the loading rate). On both support sides, LVDTs were attached to the end-face of each tensile bar via a magnetic connection and set to measure the relative end-slip of the bar against the concrete surface (see Figure B in the supplementary material).

\subsection{Cleaning of the bars}

As mentioned earlier, the bars loaded in tension were removed after the structural tests. They were cleaned by sandblasting, which was selected as a cleaning method according to the findings in [28]. The sandblasting was performed in an individual cabinet designed for the purpose, by using 5-7 bars of pressure and silica sand. Each bar was sandblasted from end to end; sandblasting is a straightforward process, wherein the cleanliness of the bar can easily be judged by visual inspection.

\subsection{Geometry acquisition of the bars}

Optical geometrical scanning measurements were used to obtain a detailed three-dimensional (3D) description of the steel surface of each bar. The measurements were done with a portable laser scanner (Handy Scan $700^{\mathrm{TM}^{2}}$ from Crea-Form ${ }^{\circledR}$ [29]), featuring an accuracy of up to $20 \mu \mathrm{m}$ and a maximum spatial resolution of the generated point cloud of $50 \mu \mathrm{m}$. The outcome of the 3D-scanning procedure consisted of a very fine $3 \mathrm{D}$ mesh of triangular elements built upon the nodes of the generated point cloud (Fig. 5). The average size of an element corresponded to $0.014 \mathrm{~mm}^{2}$, with a side length of approximately 


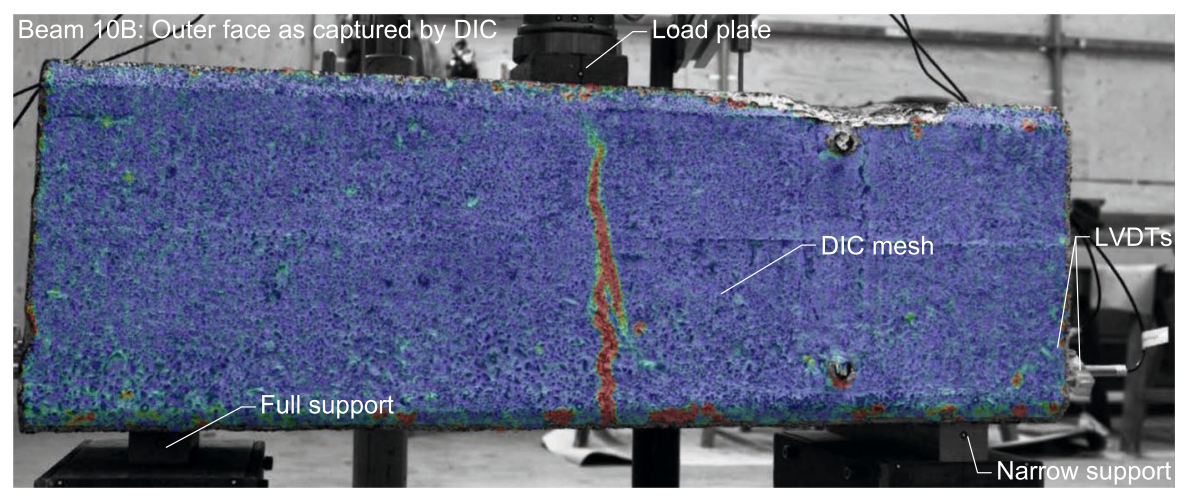

Fig. 4 Monitoring of the tests: DIC mesh of the outer side of the beam. On the right, LVDTs are magnetically connected to the tensile bars to monitor the end-slips

Superposition of the scanned area

BAR 120 FS: 3D scanning output
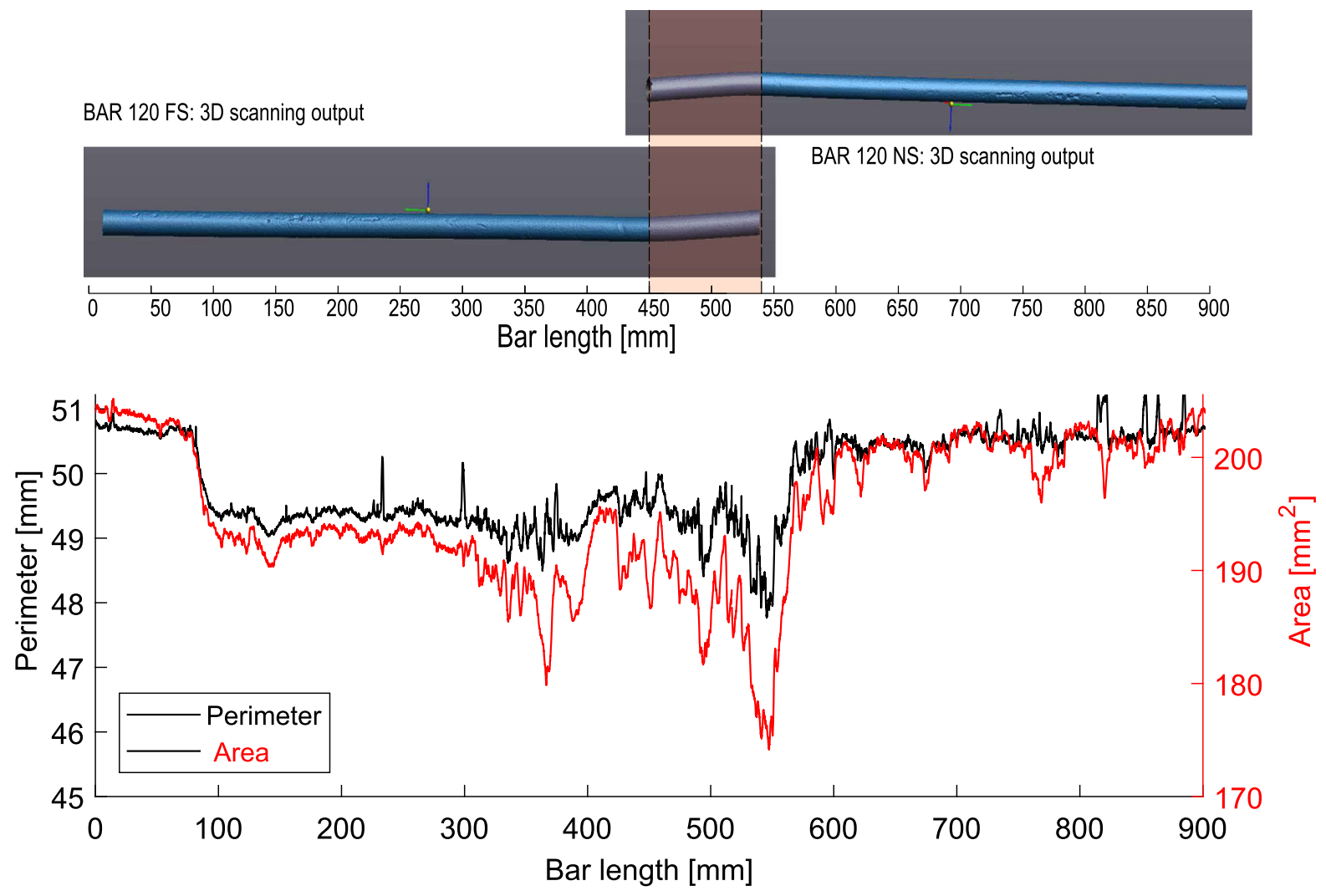

Fig. 5 Three-dimensional scanning data: mesh and processed data of one of the bars (TO, beam 10B). The yielded zone is clearly visible in the middle of the bar and denoted by a sudden decrease in the average area and the perimeter of the sections

$0.15 \mathrm{~mm}$. A global coordinate system $(X, Y, Z)$ was established and referenced to the centre of the bar. Two scans of each bar were obtained (one for each side). The high resolution of the surface mesh allowed for a sufficiently detailed description of the outer surface of the bar: data on features including pit distribution, yield penetration (Fig. 5) and loss of cross-sectional area along the bar length were 
collected. It should be noted that a data cleaning operation was performed using the post-processing software VXelements [29] before analysing the geometrical features of the bar. This was done to repair minor defects in the generated mesh, such as isolated points.

\subsection{Evaluation of the yield penetration and the corrosion level}

The optical measurement technique described in Sect. 2.6 was used to evaluate the yield penetration length and the corrosion level of the bar. Each bar was scanned in two parts, referred to as the narrow support side (NS) and full support side (FS). From the geometrical data acquired with 3D scanning, a mesh was generated. The mesh was then used to obtain the bar cross section spaced every $0.1 \mathrm{~mm}$, and from each one the area and the perimeter were evaluated (Fig. 5). The first iteration on the data recognised and divided the bar into a yielded and unyielded segment. In each scanned segment of the bar, the yield penetration was identified as the portion of the bar affected by a noticeable constant decrease in both the area and the perimeter of the cross section. It was possible to distinguish the yielded length of the bar from the corrosion damages due to the simultaneous decrease of both the area and the perimeter of the bar: in those areas where the bar was instead only affected by corrosion, the perimeter was observed to increase due to the irregularities in the surface created by the pits. The unyielded segment was then further studied to acquire

1. the average uncorroded area of the bar, defined as the area of the bar prior the corrosion process, and

2. the corrosion level (see Table 3), defined as the ratio between the average area of the bar and the uncorroded area.

Because the geometrical changes in the bars due to yielding made the evaluation of the corrosion level challenging (and hardly accurate), no estimation of the corrosion level in the yielded zone was calculated.

A high variability in the original diameter of the bars was observed. This is most likely linked to the production methods used at the time of the construction of the bridge. To increase the accuracy of the evaluation of the loss of area due to corrosion damage, the area and perimeter distribution data of each unyielded segment was analysed. Reference uncorroded values for the different bars were estimated. This was achieved by comparing the area of each section to its perimeter and analysing the difference between the actual perimeter and the perimeter of a circular section with the same area. When such comparison yielded differences smaller than $0.1 \%$ from the theoretical perimeter, the cross section was classified as uncorroded, and its area was added to compute the average uncorroded area $\left(\hat{A}_{u, \text { bar }}\right)$ of the bar in question. (For further detail on the evaluation, see Figure $\mathrm{C}$ in the suppementary material). For those cases where no uncorroded section could be identified along the length of the bar, the average uncorroded area was assumed to be equal to the average of the uncorroded sections of all the bars analysed in this study $\left(\hat{A}_{u}\right)$ (Table 1$)$. The corrosion level of the bar (Table 3 ) was then evaluated as the average loss of the cross-sectional area:

$$
C_{\text {bar }}=1-\frac{\hat{A}_{\text {bar }}}{\hat{A}_{u, \text { bar }}},
$$

where $\hat{A}_{\text {bar }}$ is the average area of the bar, as estimated from the cross-sectional area of each section of the unyielded bar segment, and $\hat{A}_{u \text {,bar }}$ is the average uncorroded area of the same segment.

\subsection{Tensile tests of the bars}

After 3D scanning, tensile tests were performed on the bars extracted from the beams. With the use of an MTS universal testing machine, 62 segments of $330 \mathrm{~mm}$ each were subjected to direct monotonic tensile tests and conducted up to failure (Figure D, supplementary material), in accordance with EN-15630-1:2010 [30]. All bar segments were tested under displacement control with a loading rate of $0.01 \mathrm{~mm} / \mathrm{s}$ up to $1.5 \mathrm{~mm}$ of elongation, followed by a loading rate of $0.1 \mathrm{~mm} / \mathrm{s}$ that was continued until failure. A length of $80 \mathrm{~mm}$ was clamped at each bar segment end (Fig. 6), through which the displacement was directly applied. Total machine displacement, as well as bar deformation, was registered during the tests. The bar segment deformation was measured using a displacement transducer with a gauge length of $50 \mathrm{~mm}$, which was positioned in the middle of the tested specimen. All the bars were cut $330 \mathrm{~mm}$ from the edge of the bar for 

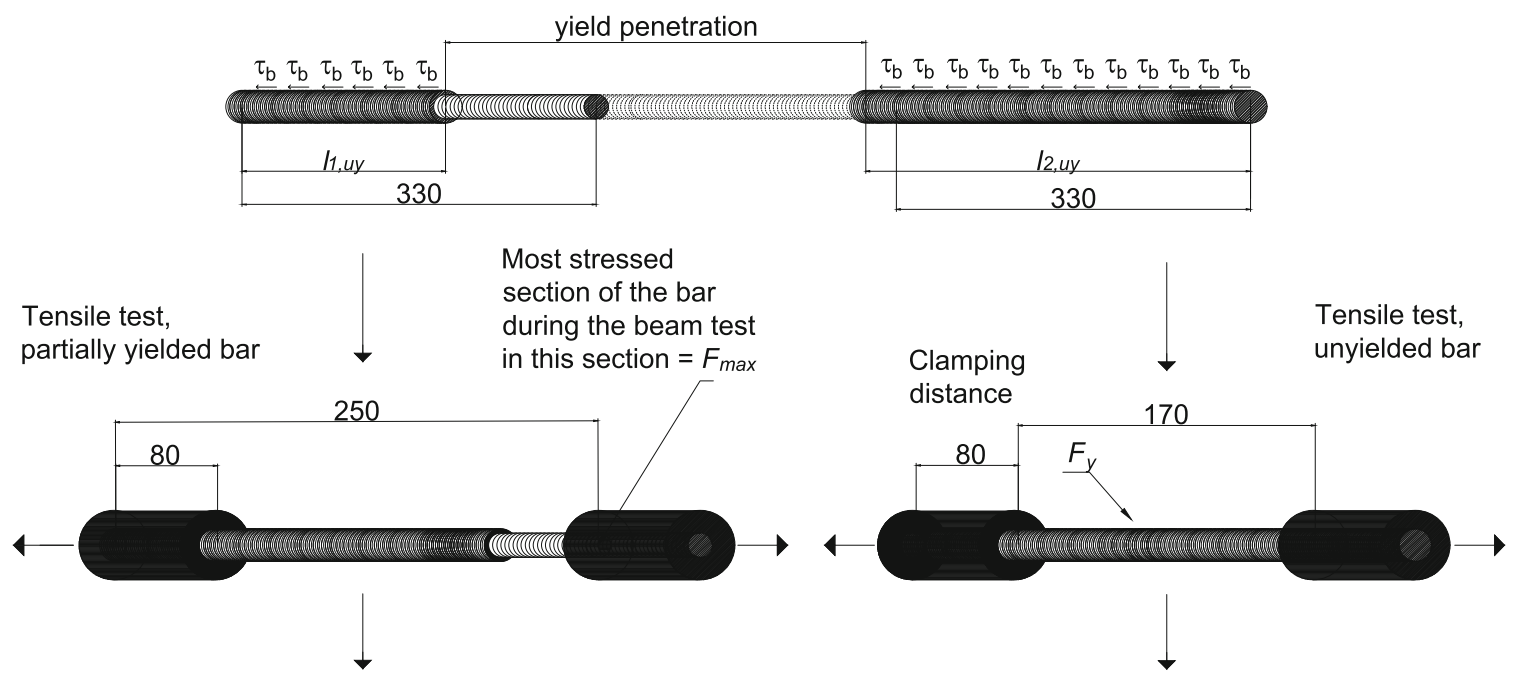

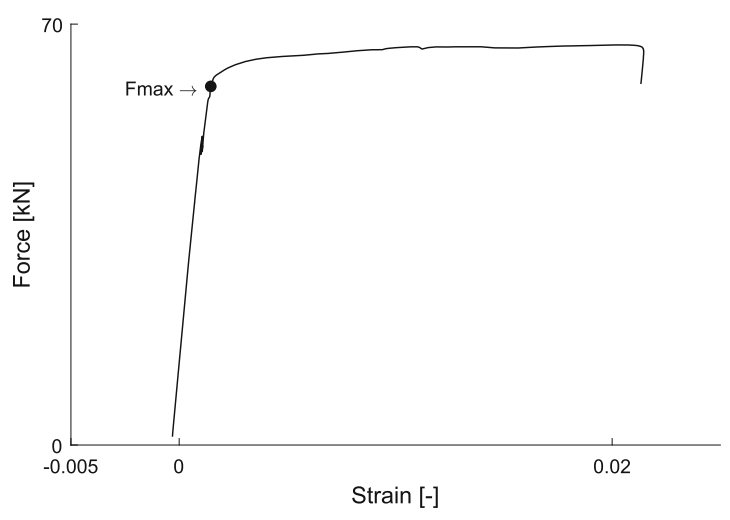

Fig. 6 The whole reinforcement bar in the beam test, together with the two segments cut for the tensile tests. The segments present different unyielded lengths $\left(l_{1, u y}\right.$ and $\left.l_{2, u y}\right)$. The different

tensile testing, for a total of 80 bar segments. Of these, 20 bar segments could not be tested owing to damage caused by the extraction process. The bar segments belonging to the side that did not fail in the beam test were always unyielded and were used to determine the yield force $\left(F_{y}\right)$. The bar segments belonging to the failure side often included an unyielded part and a part of the bar that had yielded: in this case, the maximum force $\left(F_{\max }\right)$ in the bar segment during the test was estimated (see Fig. 6). Sixty-two bar segments were tested:

1. Forty-five bar segments with no yielding in the tested zone;

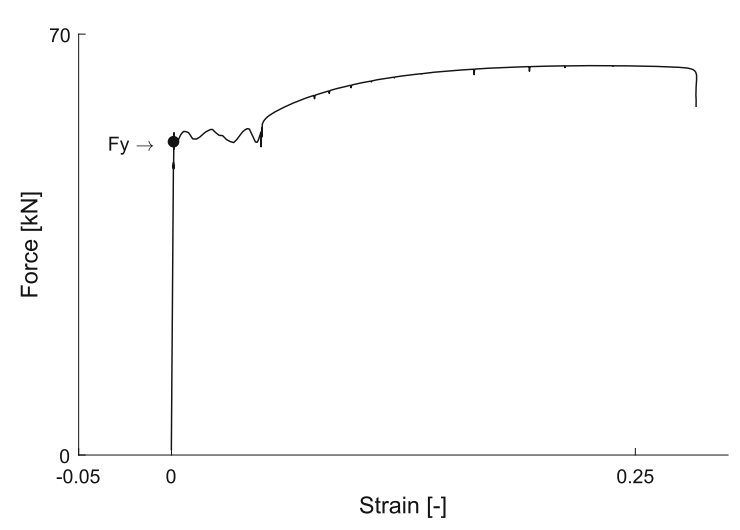

results from tensile testing are shown: (left) maximum force $\left(F_{\max }\right)$ in the beam test; (right) yield force $\left(F_{y}\right)$. Note that the $x$ axes in the two graphs have different scales

2. Fifteen bar segments that had reached hardening in the three-point bending test, in the tested zone; and

3. Two uncorroded bar segments extracted separately from the edge beams of Gullspång Bridge, in untested areas.

The two additional bar segments were cut from bars extracted from the edge beams with the aim of characterising the material properties of the steel: each bar segment was tested twice in tension, first up to hardening, and then unloaded and tested again up to failure. The results showed perfect agreement with the hypothesis of isotropic hardening, meaning that, when the bar was tested in tension for the second time, it 
showed an elastic behaviour up to the maximum tensile force reached in the previous tensile test. This implies that by testing in tension the already hardened bar segments, as extracted from the beams after structural testing, it was possible to estimate with good approximation the maximum force reached in the bar in the three point bending test.

\section{Methodology: evaluation of the bond strength}

The bond strength in the bar at the time when end-slip took place was severely affected by yield penetration. Given the reduction in diameter, the yielded zone was expected to carry a reduced bond stress. This is particularly relevant in the case of plain bars, where the bond relies mostly on friction. As described in Sects. 2.7 and 2.8, yield penetration and corrosion distribution were investigated. The unyielded and yielded parts of the bars were tested in tension. This provided useful information about the force that was applied to the bar when the tensile reinforcements began to slip. Tensile tests on unyielded segments were used to determine the yield force in the bar, while tensile tests of yielded segments were used to determine the maximum tensile force reached in the bar segment during the three point bending test. The bond strength evaluation is divided in two different cases: the case where the reinforcement bars yielded during the three-point bending test, which includes the majority of the specimens, and the case where the reinforcement bars did not yield (see also Figure E in the supplementary material). The evaluation of the average bond strength in the unyielded zones $\left(\hat{\tau}_{u y, \text { bar }}\right)$ was based on the following assumptions:

1. The unyielded length of the bar $\left(l_{u y, \text { bar }}\right)$ on the side that slipped was determined by 3D scanning, (Fig. 5).

2. The force carried by a bar at the section between the unyielded and the yielded part when the endslip was initiated was equal to the yield force, $F_{y, \text { bar }}$, i.e. the yield force was applied to the outermost yielded cross section (Fig. 6). Thus, the bar was unloading when it started to slip.

3. The yield force of each bar was evaluated from a tensile test of its unyielded part. The $330 \mathrm{~mm}$-long segment used for the tensile test was in most of the cases cut from the side of the tensile bar that did not slip, where the unyielded zone of the bar was in general longer than in the side where anchorage failure took place.

The average bond strength in the unyielded zone $\left(\hat{\tau}_{u y, \text { bar }}\right)$ of each bar was calculated as

$$
\hat{\tau}_{u y, \mathrm{bar}}=\frac{F_{y, \mathrm{bar}}}{\hat{p}_{u} l_{u y, \mathrm{bar}}},
$$

where $\hat{p}_{u}$ corresponded to the average uncorroded perimeter of the bars (Table 1), $l_{u y, \text { bar }}$ was the unyielded anchorage length of the side that slipped and $F_{y, \text { bar }}$ was the yield force of the bar (both in Table 3).

For four bars, a different evaluation of the average bond strength had to be used. The bars failed in anchorage before yielding took place or, in the case of beam 17A, the appearance of a second bending crack closer to the support resulted in the slip of the tensile bar, before yielding penetration had reached the anchorage zone. In this specific cases, the average bond strength of the unyielded bar $\left(\hat{\tau}_{u y, \text { bar }}\right)$ was evaluated as follows. The available anchorage length $\left(l_{a}\right)$ was estimated as the distance from the crack to the edge of the beam where the tensile reinforcements slipped. The distance was measured both on the rear and on the front side, and the measurement of the side closer to the bar in question was used for the evaluation of the bond strength. The axial force on the longitudinal reinforcement bar $\left(F_{t}\right)$ was calculated, assuming an inner level arm equal to $0.9 \mathrm{~d}$. The effective depth $d$ was taken as the distance between the top of the cross section and the averaged position of the tensile reinforcement bars. Thus, from the equilibrium:

$$
F_{t}=\frac{P l_{s}}{4 * 0.9 d},
$$

where $P$ was the point load applied in the beam when anchorage failure took place and $l_{s}$ was the distance between the middle of the support and the major bending crack. The tensile force was assumed to be divided equally between the two bars when the first bar started to slip. The average bond strength in the first bar to slip was then calculated as

$$
\hat{\tau}_{u y, \text { bar }}=\frac{F_{t}}{l_{a} \hat{p}_{u}}
$$


where $l_{a}$ was the available anchorage length and $\hat{p}_{u}$ corresponded to the average unyielded perimeter of the bars (Table 1). This was considered valid only for the first bar to slip. However, only in one case did the second bar not yield before failure, and the average bond strength was not evaluated for this case.

The average bond strength in the yielded zone $\left(\hat{\tau}_{y, \text { bar }}\right)$ was investigated for better understanding the impact of yielding on bond. As described in Sects. 2.7 and 2.8, some of the bars tested in tension were partially yielded within $170 \mathrm{~mm}$ of the tested length (from 80 to $250 \mathrm{~mm}$ ). This provided useful information about the force that was applied to the bar when anchorage failure occurred. The tensile tests of these bars, in fact, did not have a yielding plateau, but went directly from elastic behaviour into hardening (see Fig. 6). To evaluate the bond strength in the yielded zone, an additional assumption was made:

4. The maximum force $\left(F_{\max , b a r}\right)$ applied at a distance of $250 \mathrm{~mm}$ from the edge during the beam test was evaluated from the tensile tests of the yielded parts of each bar. $F_{\text {max,bar }}$ was equal to the force reached in the tensile test at the point where the elastic branch met the hardening branch (see Fig. 6a).

The average bond strength of the bar in the yielded zone $\left(\hat{\tau}_{y}\right)$ was then calculated as

$\hat{\tau}_{y}=\frac{F_{\text {max }, \mathrm{bar}}-F_{y, \text { bar }}}{\hat{p}_{u}\left(250 \mathrm{~mm}-l_{u y, \mathrm{bar}}\right)}$,

where $F_{\text {max bar }}$ was the maximum force in the bar during the beam test (see Fig. 6 and Table 3), $l_{u y \text {,bar }}$ was the unyielded anchorage length and $\hat{p}_{u}$ corresponded to the average uncorroded perimeter of the bars (Table 1). $F_{y, \text { bar }}$ was the yield force of the bar, resulting from the tensile test of an adjacent unyielded zone.

\section{Results and discussion}

\subsection{General behaviour of the three-point bending tests}

Twenty beams were tested in three-point bending. Slip of the tensile reinforcement bars was observed in 18 of them, after the opening of one or two bending cracks
(Table 2). Two additional beams exhibited a similar crack pattern, but were subjected to rupture of the bolts in the restrained side (see Sect. 2.3). Nine beams were tested as positioned on the bridge, whereas 11 were tested upside down with respect to their original position. All the beams were characterised by the opening of one, or a maximum of two, major bending crack(s) localised underneath the load plate (Fig. 7). Shortly after the first crack opened, yielding of the bars took place. Only four bars in three beams failed in anchorage without yielding. Slipping of the other bars took place, one at a time, between 5.7 and $18 \mathrm{~mm}$ of mid-span deflection (Fig. 8). Most often, both tensile reinforcement bars on the same side of the beam slipped; however for two specimens, one bar on each side slipped. It is worth mentioning that, in two tests (beam 17A and beam 9H), one of the bars in the compressive zone slipped during the test (in both beams, the top-inner bars, TI). Since those bars were not monitored, the point of slipping of those bars is unknown. Furthermore, during three different tests (17C, 9G, and 13C), end-slip was observed only in one of the tensile reinforcements. In these cases, the structural tests were stopped before the slip of the second bar could be observed due to safety reasons, such as the risk of the specimen falling from the test rig.

In Fig. 8, the mid-span deflection is plotted against the applied load for each three-point bending test. On each curve, the point when initiation of the end-slip was measured for each bar is marked. Different colours are used to highlight the different levels of damage of each anchorage zone, classified according to Sect. 2.2 (i.e. reference, cracks, and severe damage). Top-cast bars are marked with an asterisk, whereas bottom-cast bars are marked with a square.

Overall, the load-deflection curves of the tested specimens presented a similar behaviour, although with a large scatter in the peak load. The peak load was, in most of the cases, reached after the beam had deflected enough to reach the steel-hardening strains in the bars. In most tests, the first end-slip took place at this point. Thus, the beams were often already highly damaged at the time when the first end-slip took place: the bending cracks were visibly open, the reinforcement bars had started hardening and, sometimes, cracks due to local crushing of concrete had appeared underneath the load plate. In only three cases out of 20 did the first end-slip take place right after the opening 

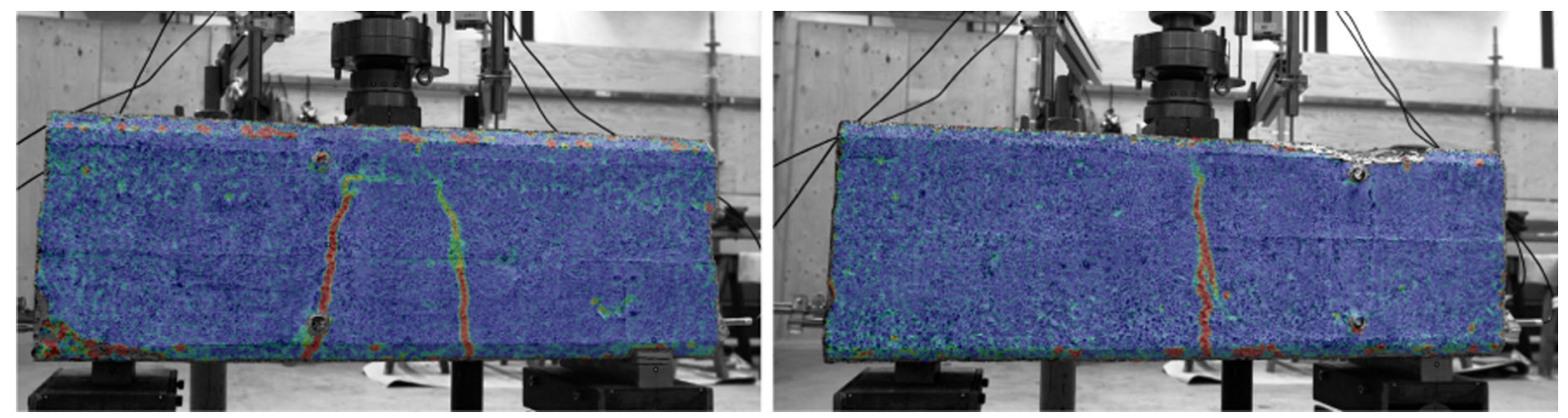

Fig. 7 Beam 17H (left) and beam 9B (right): example of typical crack patterns at the beginning of the plastic phase, as captured by DIC

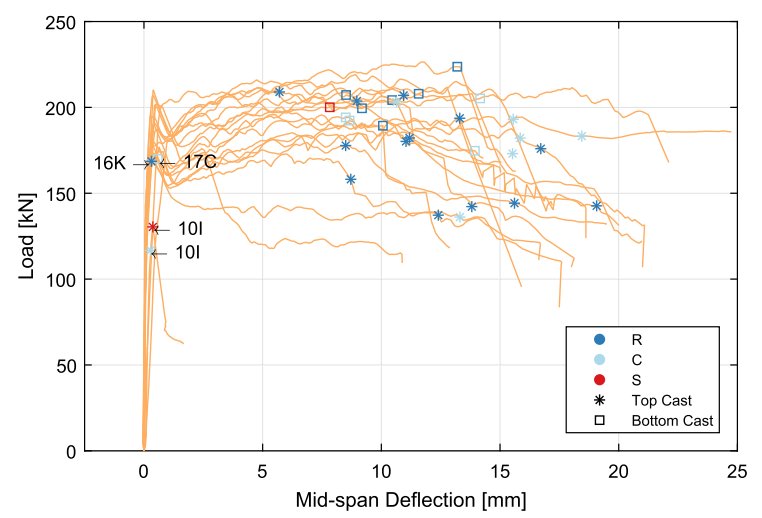

Fig. 8 Load-mid-span deflection curves for the three-point bending tests. The markers show where each bar started to slip; colours indicate the level of damage in the anchorage zone, according to Sect. 2.2. The impact of the cast position is shown by an asterisk for the top-cast bars and by a square for the bottom-cast bars. The labels of the beams where end-slip of one or more bars took place without yielding are marked. (Color figure online)

of the first bending crack. Thus, in most of the cases, the bars started to slip at a later stage, when other failure mechanisms (such as crushing of concrete or bending failure) were close to leading to the collapse of the specimen. E.g., the test of beam 13C was interrupted before the end-slip of the second tensile reinforcement could be observed, due to the excessive crushing of concrete underneath the load support. The bond strength of the bars limited the mid-span deflection of the specimen, but most likely had little effect in reducing the load-carrying capacity when it was high enough to anchor the yield force on the bar in the shear span of the beam. Only three beams can be said to have failed in anchorage. In all the others, the anchorage capacity was enough to carry the yield force, and only the effect of yielding on the bond strength led to slipping of the bars and consequently decreased the deformation capacity of the specimens.

In Fig. 9, the peak load reached in the three-point bending tests is plotted against the average bond strength of the first unyielded bar that failed in anchorage in each specimen. Only the first slip is shown to better correlate the initial loss of bond with the load-carrying capacity of the beam. It could be observed that the bond strength of the bars hardly affected the load-carrying capacity of the beam when it was higher than $3 \mathrm{MPa}$, whereas lower bond strengths, such as approximately $2 \mathrm{MPa}$, led to anchorage failure. In Figs. 8 and 9 it can be observed that, when tested upside down, the beams had, in general, a lower load-carrying capacity. This could be explained by considering that the concrete was more damaged by spalling cracks in the bottom; when tested upside down, this led to a weaker compressive zone on the top, where the rebars were often exposed. No trend could be observed between the peak load and the external damage in the bond region. This suggests that the scatter in the peak load was more a function of the overall damage in the beam or of the material and geometrical properties of the sample itself.

Although the limited bond strength of plain bars did not significantly affect the load-carrying capacity, a clear impact on the load-carrying mechanism in the post-yield range could be observed. When yielding, the bond strength of plain bars further decreased, limiting the transmission of stresses between the steel bars and the surrounding concrete. This led to the transition from beam action (the force in the bar decreases outside the high moment region and the lever arm is constant) to arch action (the lever arm decreases outside the high moment region and the force in the bars is constant) in the load-carrying 


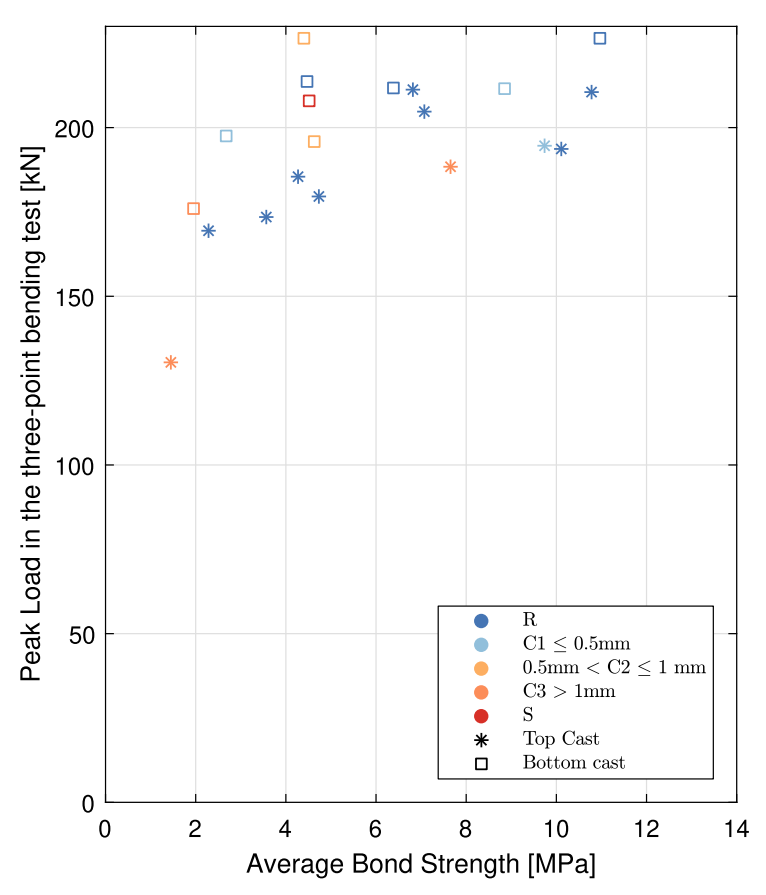

Fig. 9 Plot of the peak load reached in the three-point bending test against the average bond strength of the first bar failing in anchorage. Different colours are used to indicate the level of damage of the anchorage zone. The impact of the cast position is shown by an asterisk for the top-cast and by a square for the bottom-cast bars. (Color figure online)

mechanism. Examples of how the bond strength affects the load-carrying mechanism of flexural beams are present in the literature [31, 32]. Dong et al. [31] performed four-point bending tests on 20, artificially corroded, RC beams with deformed bars. A transition from beam to arch action was observed in the later loading stages in connection to a degraded bond capacity in the bars owing to corrosion. Feldman et al. [32] investigated the transition from beam action to arch action in flexural members with plain bars, observing the bond strength distribution along the length of the tensile reinforcements. High bond stresses were observed adjacent to the supports for beams where shear was carried principally by arch action. Arch action was associated with a marked reduction in flexural stiffness. The decrease in the bond strength in the yielded sections of the bars in the tested specimens suggested a transition from beam to arch action. The results of 3D scanning and tensile testing of the bars confirmed a more uniform distribution of stresses in the length of the bars than that expected from hand calculations. In some of the tested beams, the yield penetration reached the support. Such high stresses outside the high moment region were not possible to explain by beam action. Therefore, it was concluded that, after the yielding of the bars, the loadcarrying mechanism gradually changed from beam to arch action in the tested specimens.

\subsection{Average bond strength in the unyielded zone}

After the experiments, the steps described in Sects. 2 and 3 were followed, to estimate the average bond strength in the unyielded zone of the bars that slipped during the beam tests. The results are presented in Table 3. The average bond strength of the bars was found to be equal to $7.39 \mathrm{MPa}$, with a standard deviation of $3.33 \mathrm{MPa}$. The average bond strength of bars without damage in the anchorage region was slightly higher, with a smaller scatter $(7.61 \pm 3.00 \mathrm{MPa})$, whereas that of bars with damage was lower, but with higher scatter $(7.09 \pm 3.75 \mathrm{MPa})$. Hence, no significant difference was observed between the two categories.

In Fig. 10, the average corrosion level of the bars is presented and plotted against the calculated bond strength. The average crack opening in the concrete surrounding the bars is presented by using different colours. Results are divided by showing each cast position separately. The order of the graphs represents the original position in the cross section, and the shaded area represents the accuracy in the evaluation of the corrosion level at zero, due to the uncertainties in the reference area of the uncorroded bars (see Table 2). It is evident that bars in similar cast position had a similar behaviour, and a similar level of damage:

- Tested bottom-cast bars positioned towards the inside of the bridge (bottom-inner) had a higher capacity and were, on average, uncorroded. On the other hand, it was not possible to test any bar with visible corrosion damage in this position owing to a complete loss of concrete cover. The inner bottom corner of the bridge was not directly exposed to weather conditions, but most likely damaged by the effect of moisture. The bars in this position had either no corrosion damage or no concrete cover left, and some fell off while the edge beams where being removed from the bridge.

- Tested top-cast bars positioned towards the inside of the bridge (top-inner) had little to no corrosion 
Fig. 10 Plot of the average bond strength in the unyielded zone against the average corrosion level. Different colours are used to indicate the level of damage in the anchorage zone. Results from different positions in the cross section are displayed separately: top-outer (left, top), topinner (right, top), bottomouter (bottom, left), and bottom-inner (bottom, right). The shaded area represents the accuracy in the evaluation of the corrosion level at zero, due to the uncertainties in the reference area of the uncorroded bars. (Color figure online)
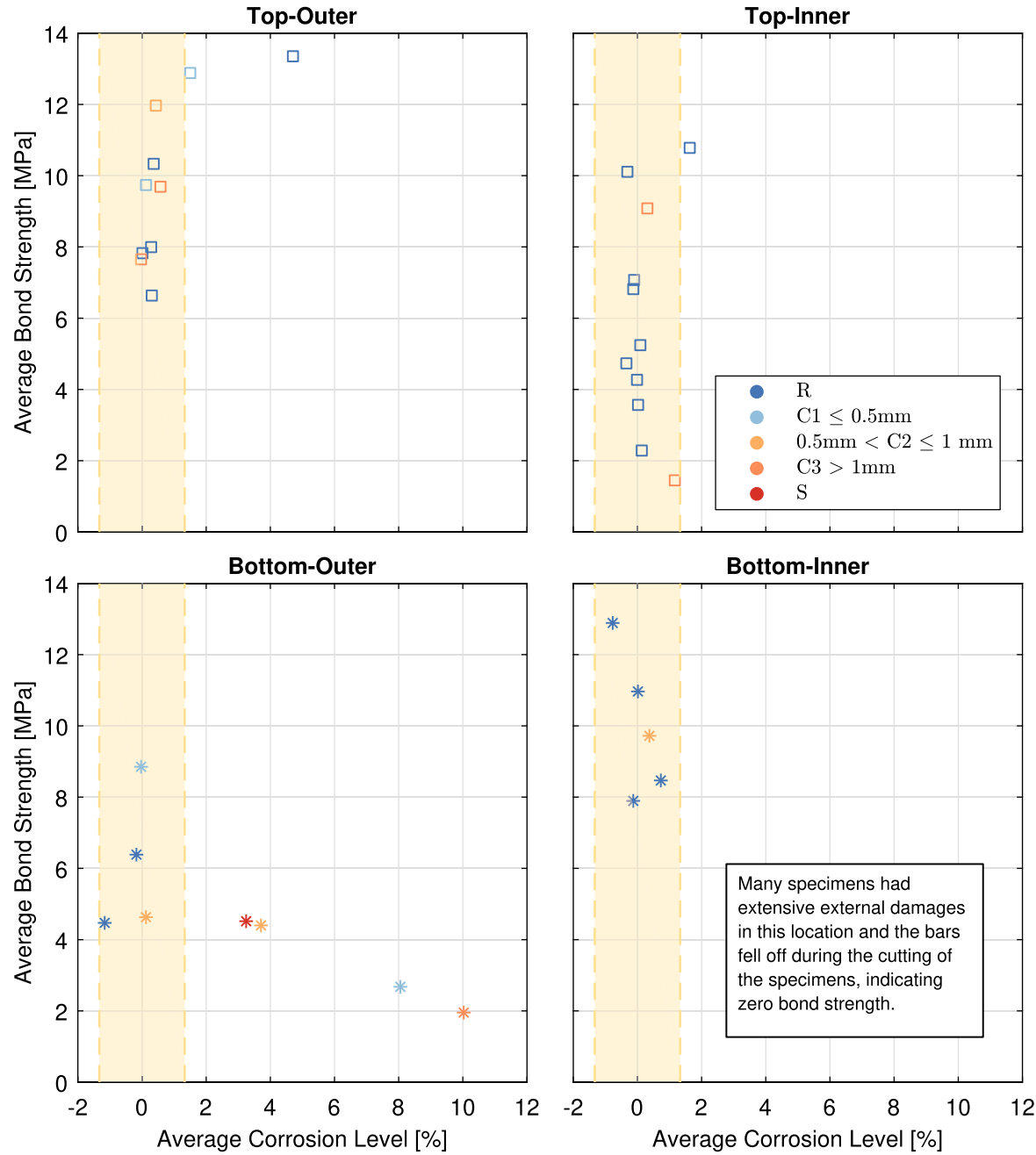

but had the lowest bond strength among the uncorroded bars. The low level of corrosion could be linked to the protective layer of asphalt that was present in this position.

- Tested top-cast bars positioned in the outer side of the edge beams (top-outer) had higher corrosion levels and a higher bond strength than those of the top-inner bars, where little to no corrosion was present.

- Tested bottom-cast bars positioned in the outer side of the edge beam (bottom-outer) had higher corrosion levels but lower bond strengths than those of the bottom-inner bars.

Beams with bottom-cast bars in tension cracked in the anchorage zone at a lower level of corrosion compared to beams with top-cast bars. Consequently, their average bond strength consistently decreased with the corrosion level. The appearance of cracks at different corrosion levels depending on the bar position can be explained by the different densities of the concrete surrounding the bar; the presence of voids leaves more room for expansion for the corrosion products. Bottom-cast bars had a higher bond strength in the uncorroded zone (7-13 MPa). This was not the case for top-cast bars: uncorroded top-cast bars occupied the lower bound of the scatter in the bond strength (between 2 and $7 \mathrm{MPa}$ ) but exhibited a higher bond strength with increasing corrosion levels. The highest bond strength (13.5 MPa) was measured in beam $14 \mathrm{H}$ (see 3 ) in a top-cast bar with $4.7 \%$ of average corrosion level but no visible damage in the concrete cover. All bottom-cast bars presented cracks in the anchorage zone if the measured corrosion level 
was higher than $2 \%$. Such a trend is in line with the findings of other authors [13], but has never been observed before in flexural tests. As for the different confinement provided by the narrow and full support, exactly half of the specimens failed on the full support side and half on the narrow side. No trend linked to the use of the two different supports could be observed. This result was unexpected, but could possibly be explained by the presence of a stirrup external to the narrow support. The increased confinement provided by the stirrup may be comparable to the increase in confinement provided by the use of a full support. Both the presence of active confinement (such as support pressure) and the presence of stirrups are in fact known factors that could increase the bond strength of plain bars [9].

In Fig. 11, the average corrosion level of the bars is compared to the peak corrosion level. This was done to obtain a better understanding of the corrosion distribution over the bar length. The shaded area represents

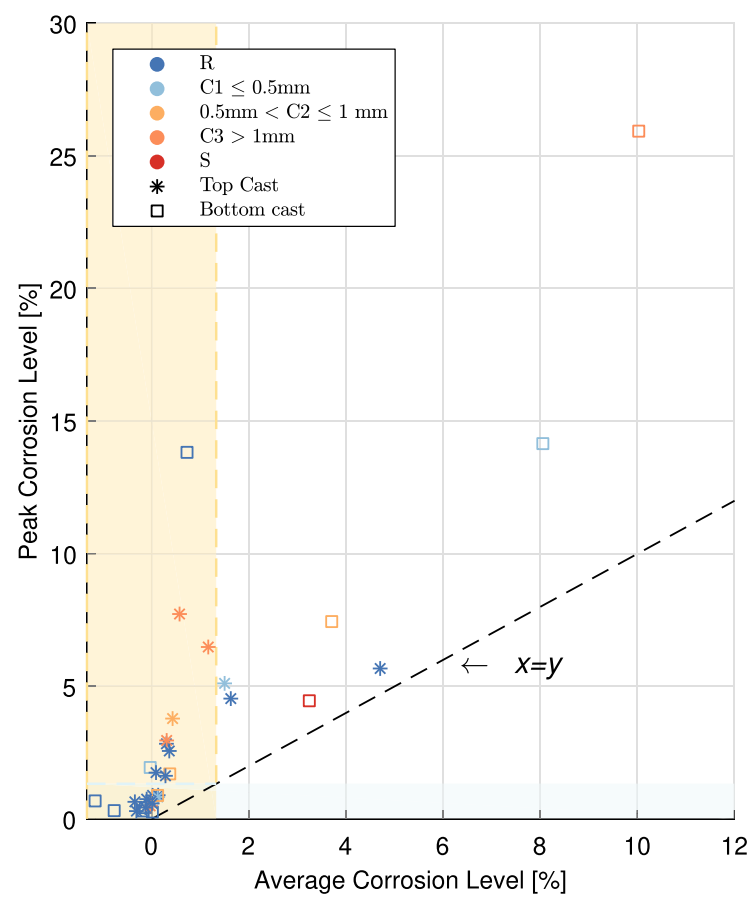

Fig. 11 Plot of the average corrosion level against the peak corrosion level of the bars. Different colours are used to indicate the level of damage of the anchorage zone. The impact of the cast position is shown by an asterisk for the top-cast bars and by a square for the bottom-cast bars. The shaded area represents the accuracy in the evaluation of the corrosion level at zero, due to the uncertainties in the reference area of the uncorroded bars. (Color figure online) the accuracy in the evaluation of zero corrosion level, for both peak and average corrosion. The dashed, inclined line indicates uniform corrosion over the length of the bar. The peak corrosion level increased logically with the average corrosion level, although few specimens were close to the uniform corrosion line; the corrosion distribution was characterised by the presence of pitting corrosion or by an alternation of corroded and uncorroded areas. It can also be observed that most of the tested bars presented an average corrosion level below $2 \%$, which was considered an unexpected result given the age of the bridge. On the other hand, it was not possible to cut specimens to test from all the length of the edge beams. Many parts had exposed reinforcements or even had lost the reinforcement bars during the cutting process. It is likely that this damage was caused by a higher amount of corrosion than that in the tested specimens. Many bars with more than $8-10 \%$ average cross-section loss had approximately zero bond strength remaining.

It is interesting to note that the bond strength evaluated in this work was, on average, significantly higher than the data available in the literature. This conclusion even acknowledges the high scatter in the results. However, no previous investigation on the anchorage capacity of flexural members with plain naturally corroded reinforcement bars was found in the literature; therefore, when comparing with results from other authors, it is important to be aware of the differences in both the methodology and the materials. Cairns et al. [11] investigated the effect of reinforcement corrosion on concrete beams reinforced with artificially corroded plain bars (up to $10 \%$ corrosion level). An increase in strength of the corroded beams was registered and linked to the increase in bond strength owing to moderate corrosion of the bars and to the consequent increase in radial stresses. No decrease in the strength of the bars was observed after corrosion, and it was concluded that the increase in bond was able to offset the loss of bar section. Moreover, the bond strength was found to be higher than the estimation obtained by using the empirical relationship [13]. However, the measured bond strength ranged between 1 and $3 \mathrm{MPa}$, which is much lower than the average bond strength measured in the tests presented in this paper. The difference in the results could be explained by considering the different evaluation choices between the two experiments. Cairns et al. also observed yielding of the tensile 
reinforcement but evaluated the average bond strength in the whole anchorage length, defined as the distance between the end of the beam or bar and a point at an effective depth from the load point. Moreover, many of the presented bond stresses corresponded to the maximum bond evaluated in beams subjected to flexural failure, where no end-slip of the bars was observed.

Numerous empirical and simplified relationships are provided in the literature to estimate the bond strength of non-corroded plain bars embedded in concrete, often as a result of a large number of pull-out tests [33-36]. Verderame et al. [34] estimated the maximum bond strength to $31 \%$ of the square root of the concrete cylindrical compressive strength, in megapascal. Melo et al. [35] and Feldman and Bartlett [36] agreed on the dependence of the bond strength on the concrete compressive strength, but considered also the yield stress of steel (Melo et al.) and the surface roughness and the development length (Feldman and Barlett). All the experimental results presented in these works had less than $3 \mathrm{MPa}$ of maximum bond strength. However, in pull-out tests by Fang et al. [37], the bond strength of plain bars with different levels of artificial corrosion was measured, which ranged between 2 and $17 \mathrm{MPa}$. The bond strength was shown to increase with the corrosion level, and similar bond strength to that observed in this work was recorded for bars with small levels of corrosion. The difference in casting techniques in older structures was expected to have affected the results. The concrete used for the construction of Gullspång Bridge was, in fact, manually stamped, instead of being vibrated. A study [38] presented the differences in the bond strength of plain bars when pull-out tests were carried out on samples where the concrete was stamped or on identical specimens where the concrete was vibrated. The tests with the stamped concrete exhibited an average bond strength four times higher than that in the tests where the concrete was vibrated (1.5 MPa and 0.36 MPa, respectively). Another possible influence parameter is the surface roughness of the bars. Feldman and Bartlett [36] investigated the impact of the roughness of plain reinforcement bars and suggested sandblasting as a means to increase the roughness of new bars in a laboratory test, to better represent the reinforcement bars used in the past. Gustavson [39] studied the impact of concrete density and surface roughness on the bond response of three-wire strands and found that an increase in the micro-roughness of the strand surface strongly increased adhesion in the initial bond response. An increase in bond strength for noncorroded bars linked to the increase in concrete density was also recorded. To conclude, in this work, the impact of different parameters, such as the casting position and the corrosion level, was investigated. However, it was not feasible to consider the scatter in the compressive strength since the concrete compressive strength varied significantly between samples that were taken next to each other. For this reason, it was impossible to know with adequate accuracy the compressive strength of the anchorage zone surrounding each bar.

\subsection{Average bond strength in the yielded zone}

The average bond strength in the yielded zone, evaluated as described in Sect. 3, is plotted in Fig. 12 against the yielded length of the segment on which it was measured. The results presented a rather small scatter, with a clear average of approximately $1 \mathrm{MPa}$. On the other hand, data were only collected from bars that were hardening close to the supports: the bars were bent in correspondence with the bending cracks, and the results from tensile tests on bent bars were not considered a reliable option. Thus, few data are available, only from bars with long yield penetration; these bars had a bond strength in the unyielded zone of $10.54 \mathrm{MPa}$ with a standard deviation of 1.70 MPa. However, a noticeable loss of bond

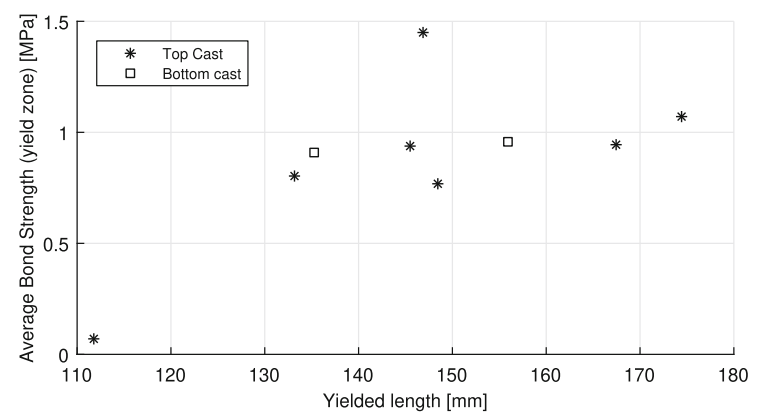

Fig. 12 Plot of the average bond strength in the yielded zone against the length of the yielded zone in the tested bar. The impact of the cast position is shown by an asterisk for the topcast bars and by a square for the bottom-cast bars 
strength after yielding could be observed. The yielded bond strength was about $10 \%$ of the unyielded bond strength. As can be seen in the figure, the original position in the cross section did not affect the result to any major extent. It can also be observed that, over a length of 100-200 mm, the difference in force in the bar is quite low, which is coherent with the hypothesis of arch action as a load-carrying mechanism. A very low bond strength was observed for one bar with a short yielded length, which might be considered counter-intuitive. This particular case could, however, be linked to the presence of a large corrosion pit in the yielded zone of the bar.

\section{Conclusions and outlook}

Assessing the bond behaviour of existing structures damaged by natural corrosion presents many challenges. This study contributes to the assessment of the bond performance of flexural members. In the context of the experimental campaign, the following was observed:

- For all but three beams, yielding of the reinforcement bars limited the load-carrying capacity. After yielding, anchorage failure took place and the bond strength thus limited the deformation capacity of the beams.

- For the remaining three beams, the bond strength of the bars limited the load-carrying capacity, leading to anchorage failure. In these cases, the bond strength of the bars was less than $3 \mathrm{MPa}$ and, therefore, the bars were not able to carry the yield stress.

- The scatter in the results was large, probably owing to the already large variations in bond behaviour for uncorroded plain bars and to the stochastic nature of the natural corrosion process, possibly also due to the variations in materials and production methods used in the 80-year-old specimens.

Based on the results of this study, the following observations were drawn:
- In the majority of the three-point bending tests, the loss of bond strength after yielding led to a change in the load-carrying mechanism, from beam to arch action. The loss of bond at yielding is often neglected when assessing structures with deformed bars, but it is of high significance in structures with plain bars.

- The average bond strength observed in the tests was $7.39 \mathrm{MPa}$, which is much higher than that reported in the literature (between 0 and $3 \mathrm{MPa}$ ): different casting techniques, the effect of natural corrosion and the difference in surface roughness of the steel bars are possible factors explaining such differences. When assessing older structures, such factors should be investigated and taken into account.

- The casting position, and, consequently, the concrete density around the bar, was recognised as an important factor for the anchorage of plain bars.

- When uncorroded, bottom-cast bars had a higher bond strength than that of top-cast bars. Furthermore, corrosion decreased the bond strength of bottom-cast bars and led to the opening of spalling cracks, whereas small corrosion levels increased the bond strength for top-cast bars. Similar trends were observed in pull-out tests of plain corroded bars by Cairns et al. [13].

To conclude, 20 beams with naturally corroded plain bars were tested in three-point bending (Tables 2 and 3). The three-point bending tests are part of a larger experimental campaign that aims at investigating the effect of natural corrosion on the anchorage of plain bars by testing specimens from Gullspång Bridge (1935, Sweden). Further structural tests are planned to complete and compare these findings: from the same edge beams, 174 pull-out tests and 7 beams with bars anchored by using hooks are currently being tested. The aim is to investigate local bond-slip curves by using pull-out tests, as well as to provide a more comprehensive overview of the anchorage of structures with plain bars, by including the effect of hooks. 


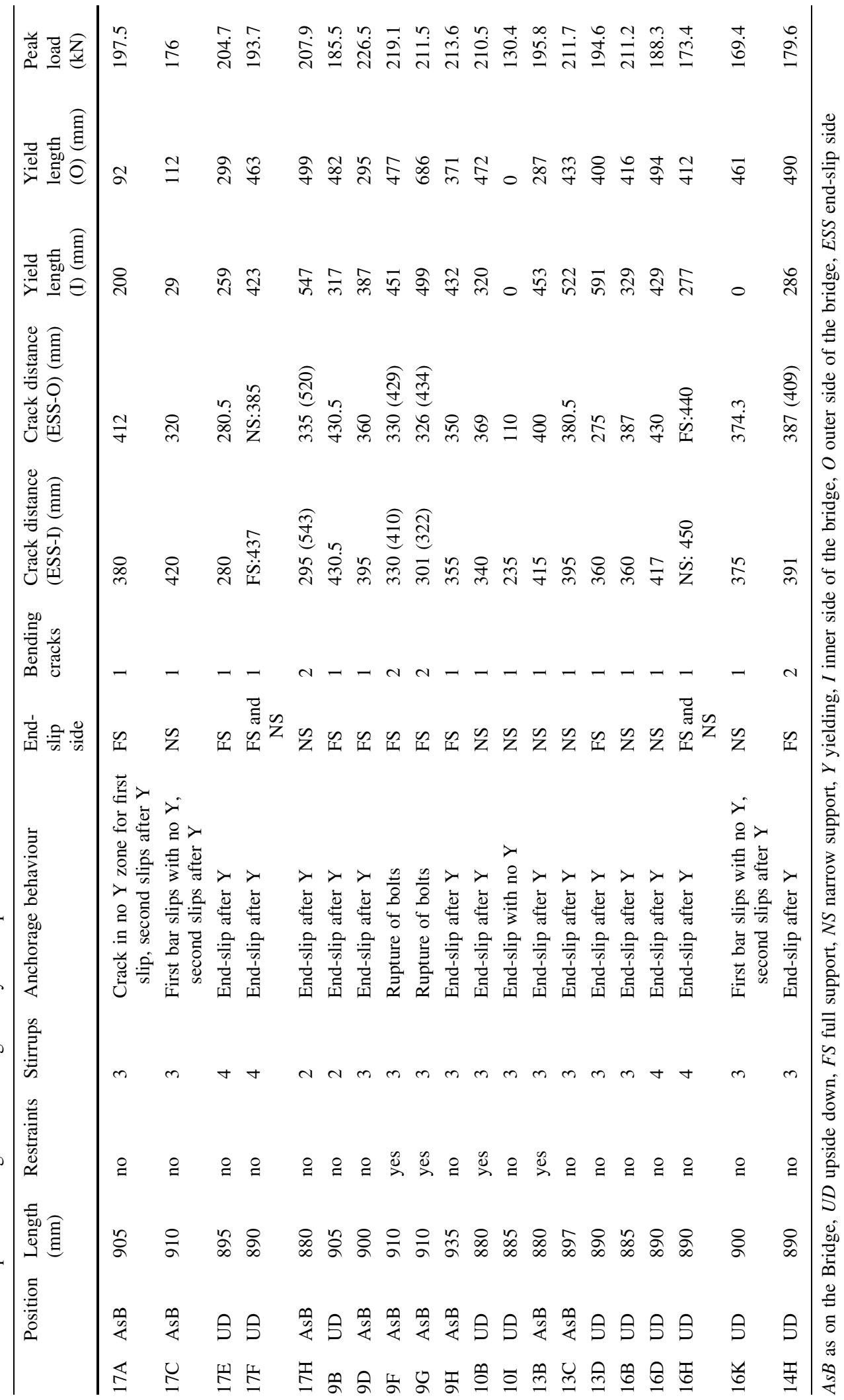




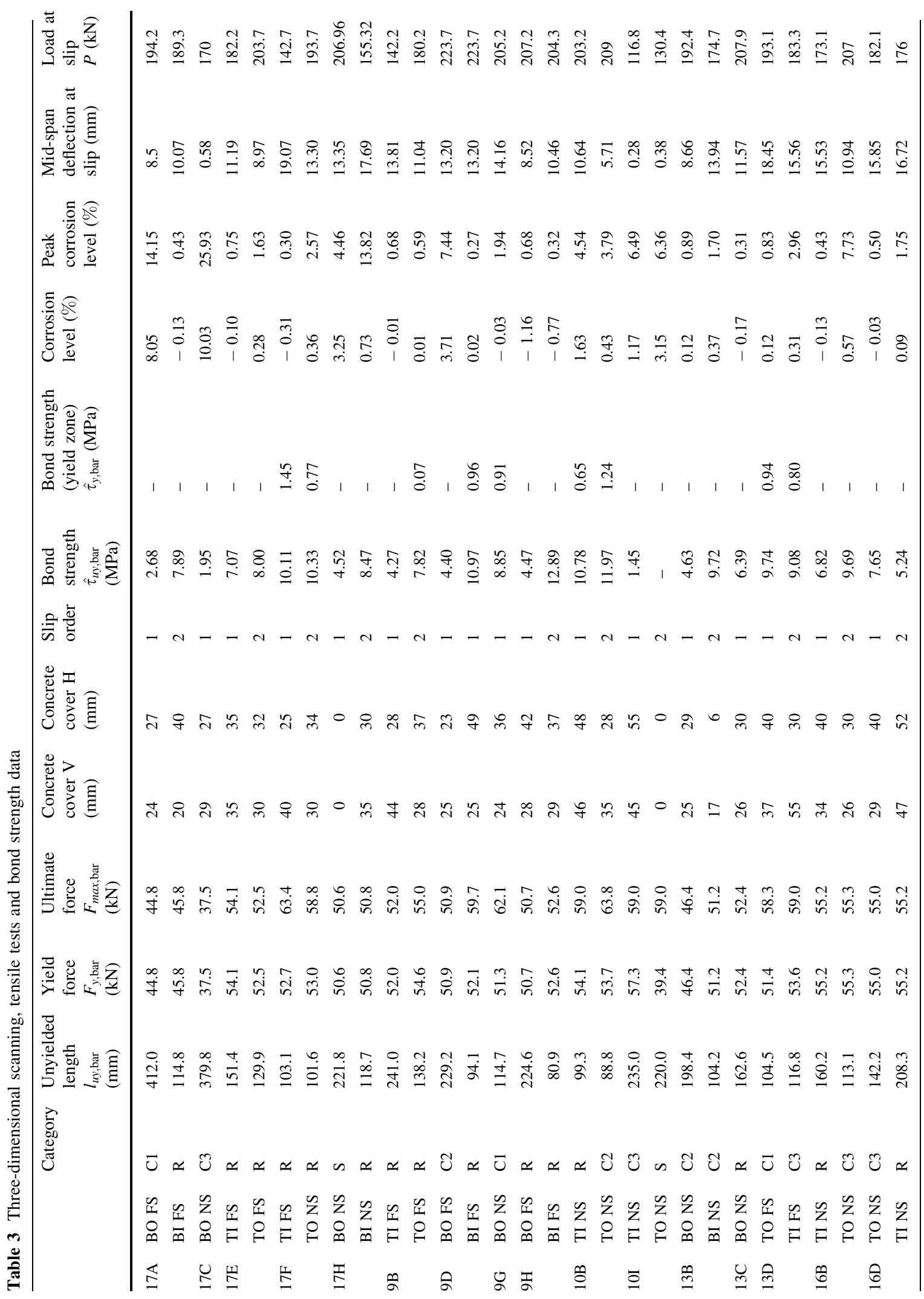




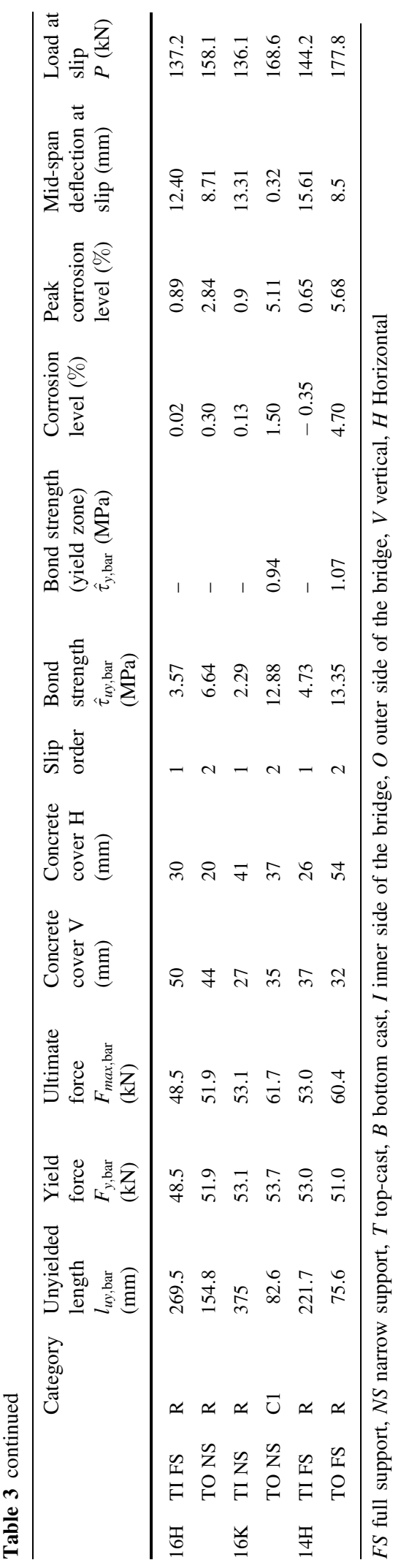

Acknowledgments Open access funding provided by Chalmers University of Technology.

Funding The work was funded by the Swedish research council Formas and the Swedish Transport Administration.

Open Access This article is licensed under a Creative Commons Attribution 4.0 International License, which permits use, sharing, adaptation, distribution and reproduction in any medium or format, as long as you give appropriate credit to the original author(s) and the source, provide a link to the Creative Commons licence, and indicate if changes were made. The images or other third party material in this article are included in the article's Creative Commons licence, unless indicated otherwise in a credit line to the material. If material is not included in the article's Creative Commons licence and your intended use is not permitted by statutory regulation or exceeds the permitted use, you will need to obtain permission directly from the copyright holder. To view a copy of this licence, visit http://creativecommons.org/licenses/by/4.0/.

\section{References}

1. Wang X, Stewart MG, Nguyen M (2012) Impact of climate change on corrosion and damage to concrete infrastructure in Australia. Clim Change 110(3-4):941-957

2. Kioumarsi MM, Hendriks MAN, Kohler J, Geiker MR (2016) The effect of interference of corrosion pits on the failure probability of a reinforced concrete beam. Eng Struct 114:113-121

3. Mattias B, Kamyab Z, Karin L, Dario C (2018) Engineering bond model for corroded reinforcement. Eng Struct 156(December 2017):394-410

4. Khan I, François R, Castel A (2014) Prediction of reinforcement corrosion using corrosion induced cracks width in corroded reinforced concrete beams. Cem Concr Res 56:84-96

5. Fabbrocino G, Verderame GM, Manfredi G (2002) Experimental behaviour of straight and hooked smooth bars in existing R.C. buildings. In: 12th European conference of earthquake engineering, p 393

6. Feldman LR, Cairns J (2017) Assessing historical provisions for bond of plain bars. ACI Mater J 114(2):463-473

7. Verderame GM, Ricci P, Esposito M, Sansiviero FC (2011) Le Caratteristiche Meccaniche degli Acciai Impiegati nelle Strutture in c.a. realizzate dal 1950 al 1980. XXVI Convegno Nazionale AICAP

8. Bell B (2004) Sustainable bridges. European railway bridge problems D1.3

9. Lundgren K (2007) Effect of corrosion on the bond between steel and concrete: an overview. Mag Concr Res 59(6):447-461

10. Abrams D (1913) Test of bond between concrete and steel. $\mathrm{PhD}$ thesis

11. Cairns J, Du Y, Law D (2008) Structural performance of corrosion-damaged concrete beams. Mag Concr Res 60(5):359-370 
12. ACI Committee 408 (2003) ACI 408R-03 bond and development of straight reinforcing bars in tension. American Concrete Institute, pp 1-49

13. Cairns J, Du Y, Law D (2006) Residual bond strength of corroded plain round bars. Mag Concr Res 58(4):221-231

14. Cairns J, Du Y, Law D (2007) Influence of corrosion on the friction characteristics of the steel/concrete interface. Constr Build Mater 21(1):190-197

15. Tahershamsi M, Zandi K, Lundgren K, Plos M (2014) Anchorage of naturally corroded bars in reinforced concrete structures. Mag Concr Res 66(14):729-744

16. Sæther I (2011) Bond deterioration of corroded steel bars in concrete. Struct Infrastruct Eng 7(6):415-429

17. Austin SA, Lyons R, Ing MJ (2004) Electrochemical behavior of steel-reinforced concrete during accelerated corrosion testing. Corrosion 60(2):203-212

18. Saifullah M, Clark LA (1994) Effect of corrosion rate on the bond strength of corroded reinforcement. In: Proceedings of international conference on corrosion and corrosion protection of steel in concrete, pp 591-602

19. Yuan Y, Ji Y, Shah S (2007) Comparison of two accelerated corrosion techniques for concrete structures. ACI Struct J 104:344-347

20. Williamson SJ, Clark LA (2002) Effect of corrosion and load on reinforcement bond strength. Struct Eng Int 12(2):117-122

21. François R, Khan I, Dang H (2013) Impact of corrosion on mechanical properties of steel embedded in 27-year-old corroded reinforced concrete beams. Mater Struct/Materiaux et Constructions 46(6):899-910

22. EN 12504-1 (2009) Testing concrete in structures. Cored specimens. Taking, examining and testing in compression. Standard, European Standardization, Brussels, Belgium, 2009

23. EN 12390-3 (2009) Testing harded concrete. Part 3: compressive strength of test specimens. Standard, European Standardization, Brussels, Belgium, 2009

24. Robuschi S, Lundgren K, Fernandez I, Zandi K, Flansbjer M (2018) Anchorage capacity of corroded smooth reinforcement bars in existing reinforced structures. In: Proceedings of the 12th fib international phd symposium in civil engineering, pp 1039-1046

25. Lundgren K, Robuschi S, Zandi K (2019) Methodology for testing rebar-concrete bond in specimens from decommissioned structures. Int J Concr Struct Mater 13:38

26. GOM GmbH. Aramis adjustable. https://www.gom.com/ metrology-systems/aramis/aramis-adjustable.html
27. GOM GmbH. Gom correlate. https://www.gom.com/3dsoftware/gom-correlate.html

28. Fernandez I, Lundgren K, Zandi K (2018) Evaluation of corrosion level of naturally corroded bars using different cleaning methods, computed tomography, and 3D optical scanning. Mater Struct/Materiaux et Constructions 51(3):1-13

29. Creaform. Vxelements. https://www.creaform3d.com/en/ metrology-solutions/3d-applications-software-platforms

30. EN 15630-1 (2010) Steel for the reinforcement and prestressing of concrete-est methods-Reinforcing bars, wire rod and wire. Standard, European Standardization, Brussels, Belgium, 2010

31. Dong W, Ye J, Murakami Y, Oshita H, Suzuki S, Tsutsumi $T$ (2016) Residual load capacity of corroded reinforced concrete beam undergoing bond failure. Eng Struct 127:159-171

32. Feldman LR, Bartlett FM (2008) Bond in flexural members with plain steel reinforcement. ACI Struct J 105(5):552-560

33. Verderame GM, Ricci P, De Carlo G, Manfredi G (2009) Cyclic bond behaviour of plain bars. Part I: experimental investigation. Constr Build Mater 23(12):3499-3511

34. Verderame GM, De Carlo G, Ricci P, Fabbrocino G (2009) Cyclic bond behaviour of plain bars. Part II: analytical investigation. Constr Build Mater 23(12):3512-3522

35. Melo J, Rossetto T, Varum H (2015) Experimental study of bond-slip in RC structural elements with plain bars. Mater Struct/Materiaux et Constructions 48(8):2367-2381

36. Feldman LR, Bartlett FM (2005) Bond strength variability in pullout specimens with plain reinforcement. ACI Struct J 867(6): 102-860

37. Fang C, Lundgren K, Chen L, Zhu C (2004) Corrosion influence on bond in reinforced concrete. Cem Concr Res 34(11):2159-2167

38. Krus J, Sundquist H (1998) Tranebergsbron i stockholm. provning och bedömning av vidhäftningen fär släta armeringsstänger. Teknisk rapport 15:1-27

39. Gustavson R (2004) Experimental studies of the bond response of three-wire strands and some influencing parameters. Mater Struct/Materiaux et Constructions 37(266):96-106

Publisher's Note Springer Nature remains neutral with regard to jurisdictional claims in published maps and institutional affiliations. 